\title{
Metodologias de avaliação de programas e projetos sociais: análise de resultados e de impacto
}

\author{
Tereza Cristina Cotta
}

\section{Introdução}

Apesar de ser um tema recorrente na literatura, a avaliação de programas sociais ainda não foi incorporada ao cotidiano da administração pública. Em parte devido a complexidade inerente às metodologias de avaliação, em parte devido ao desinteresse dos policy makers e à desconfiança dos responsáveis pelos programas, têm-se deixado de lado um poderoso instrumento gerencial, capaz de subsidiar o processo decisório e de lançar luz sobre a lógica das intervenções na realidade social. Isto se torna ainda mais preocupante em um contexto de crise fiscal, no qual os administradores são compelidos a direcionar os escassos recursos de que dispõem para os programas e projetos que melhor os utilizem. Cabe lembrar ainda que, em ambientes democráticos, cresce a demanda da sociedade organizada pela transparência na gestão de recursos públicos, o que só é possível com a avaliação sistemática das ações empreendidas pelo governo.

Este trabalho visa analisar as metodologias de avaliação de programas e projetos sociais, enfatizando uma modalidade avaliativa específica, as análises de resultados e de impacto. Preliminarmente, são apresentados conceitos básicos como a própria definição de avaliação e as noções de projeto, programa e plano. Em seguida, as tipologias de avaliação consagradas pela literatura são brevemente comentadas, permitindo que, na seção subseqüente, as análises de resultados e de impacto sejam objetos de um exame mais cuidadoso. As considerações finais arrolam as críticas aos modelos tradicionais de avaliação, suscitando uma reflexão sobre as potencialidades da pesquisa avaliativa na área social.

Mestre em Ciência Política pelo DCP/ FAFICH/UFMG e Especialista em Políticas Públicas e Gestão Governamental 


\section{Conceitos básicos}

\subsection{Projeto, programa e plano}

Segundo Cohen e Franco (1993: 85-6), os termos projeto, programa e plano designam modalidades de intervenção social que diferem em escopo e duração. O projeto é a unidade mínima de destinação de recursos, que, por meio de um conjunto integrado de atividades, ${ }^{1}$ pretende transformar uma parcela da realidade, suprindo uma carência ou alterando uma situação-problema. ${ }^{2} \mathrm{O}$ conjunto de projetos que visam aos mesmos objetivos é denominado programa, que "estabelece as prioridades da intervenção, identifica e ordena os projetos, define o âmbito institucional e aloca os recursos a serem utilizados". O plano, finalmente, agrega programas afins, estabelecendo um quadro de referências mais amplo para a intervenção:

"Um plano é a soma dos programas que procuram objetivos comuns, ordena os objetivos gerais e os desagrega em objetivos específicos, que constituirão por sua vez os objetivos gerais dos programas. Ele determina o modelo de alocação de recursos resultante da decisão política e dispõe as ações programáticas em uma seqüência temporal de acordo com a racionalidade técnica das mesmas e as prioridades de atendimento (...). O plano inclui a estratégia, isto é, os meios estruturais e administrativos, assim como as formas de negociação, coordenação e direção". (COHEN e FRANCO, 1993: 86)

Grosso modo, pode-se dizer que o plano contém o programa, que, por sua vez, contém o projeto. Isto significa que estes níveis de agregação devem ser levados em conta quando uma intervenção é analisada. Por exemplo, não se pode avaliar adequadamente um programa sem atentar para os projetos que o constituem, nem tampouco avaliar um projeto desconsiderando sua articulação com uma iniciativa mais abrangente. É possível, no entanto, mensurar o alcance dos objetivos gerais de um programa sem indagar sobre os objetivos específicos de cada projeto. Feitas estas ressalvas, nada impede que se discuta as metodologias de avaliação num nível mais alto de generalização, sem a pretensão de esgotar as especificidades da avaliação de projetos, programas e planos. De maneira geral, porém, a análise se refere às duas modalidades mais desagregadas de intervenção, a saber, projetos e programas.

Os principais conceitos pertinentes à área de avaliação serão introduzidos ao longo do texto (objetivos, metas, população-alvo, efeitos, impacto, processos, resultados, eficácia, eficiência e efetividade). Porém, cabe adiantar que as intervenções são classificadas segundo seus objetivos 
e sua abrangência (Posavac e CAREY, 1992). Há programas e projetos que visam suprir necessidades agudas e temporárias, outros que pretendem enfrentar problemas duradouros, e outros que almejam prevenir problemas futuros e/ou desenvolver o potencial humano. As intervenções podem ser ainda nacionais, regionais ou locais (focalizadas). É evidente que as especificidades de cada intervenção influenciam a escolha da metodologia de avaliação mais adequada.

\subsection{A definição de avaliação}

A principal característica da avaliação de programas é, certamente, seu caráter aplicado. Aliás, é este o norte que os avaliadores não podem perder de vista, sob pena de produzir trabalhos desprovidos de utilidade prática. Como salientam Posavac e Carey (1992), esta modalidade de pesquisa visa atender às demandas informacionais dos administradores de dado programa ou projeto:

"Basic research concerns questions of theoretical interest, without regard to the immediate needs of people or organizations. In contrast, program evaluations include information to help people improve their effectiveness, assist administrators make program-level decisions, and make it possible for programs to be accountable to the public. If evaluators do not provide information that is relevant to decisions, they are not fulfilling their major purpose”. (PoSAVAC and CAREY, 1992: 7)

De maneira consistente com este pressuposto, os autores definem a avaliação de programas, especificando os tipos de informação que ela deve fornecer:

"Program evalutation is a collection of methods, skills, and sensitivities necessary to determine whether a human service is needed and likely to be used, whether it is sufficiently intense to meet the unmet need identified, whether the service is offered as planned; and whether the human service actually does help people in need at a reasonable cost without undesirable side effects". (PoSAVAC e CAREY, 1992: 1)

Note-se que a definição compreende aspectos que se referem à concepção do programa (compatibilidade entre os objetivos da intervenção e as necessidades da clientela e quantum de serviços oferecidos), à sua estratégia de implementação e a seus resultados e impacto. Os autores mencionam também os custos e os efeitos secundários do programa. As definições encontradas na literatura abrangem basicamente as mesmas dimensões, à exceção da primeira (custos), que alguns especialistas consideram inadequada à análise de programas sociais: 
“...A avaliação é uma forma de pesquisa social aplicada, sistemática, planejada e dirigida; destinada a identificar, obter e proporcionar, de maneira válida e confiável, dados e informação suficiente e relevante para apoiar um juízo sobre o mérito e o valor dos diferentes componentes de um programa (tanto na fase de diagnóstico, programação ou execução), ou de um conjunto de atividades específicas que se realizam, foram realizadas ou se realizarão, com o propósito de produzir efeitos e resultados concretos. Visam comprovar a extensão e o grau em que se deram essas conquistas, de forma tal que sirva de base ou guia para uma tomada de decisões racionais e inteligentes entre cursos de ação, ou para solucionar problemas e promover o conhecimento e a compreensão dos fatores associados ao êxito ou ao fracasso de seus resultados..." (AGUILAR e ANDER-EGG, 1994: 31-2).

Pode-se inferir, com base nesta definição, que a avaliação pode e deve ser feita concomitantemente às outras fases do ciclo das políticas públicas, a saber, construção da agenda, formulação e implementação, dado que em todas elas há decisões importantes a serem tomadas. Assim, dependendo do momento em que é realizada e das necessidades de quem a encomenda, a pesquisa avaliativa serve a múltiplos propósitos, como, por exemplo, orientar ajustes em programas em andamento, determinar até que ponto foram alcançados os objetivos ${ }^{3}$ previamente estabelecidos, apontar as razões dos êxitos e fracassos de um programa e investigar os efeitos imprevistos (positivos ou negativos) da intervenção.

No entanto, nem sempre é possível levar adiante o processo avaliativo. O primeiro passo para analisar as condições de "avaliabilidade" de um programa ou projeto é identificar os principais atores envolvidos, seus interesses e cursos potenciais de ação:

"Stakeholders are those who are personally involved in the program, who derive some or all their income from the program, whose future status or career might be affected by the quality of the program, or who are the clients or potencial recipients of the program services”. (PoSAVAC e CAREY, 1992: 28)

Posavac e Carey falam em três tipos de atores: os program sponsors, que correspondem a agências de fomento, órgãos governamentais ou a cúpula da instituição responsável pelo programa, a equipe propriamente dita, formada pelos gestores e pelo pessoal técnico e administrativo, e os clientes ou beneficiários, indivíduos ou grupos que podem ou não ser chamados a participar das decisões pertinentes à intervenção. O comportamento destes atores é informado por racionalidades que, muitas vezes, 
entram em choque. Os program sponsors, não raro, utilizam critérios políticos para tomar decisões e fixar os grandes objetivos dos programas; os burocratas, em princípio, orientam-se pelas normas e procedimentos pré-estabelecidos, e o corpo técnico, também em tese, recorre à expertise para avalizar suas opiniões e atitudes. Isso sem falar nos recursos de poder controlados pelos destinatários dos programas, que podem pressionar direta ou indiretamente o governo para fazer valer seus interesses.

De modo geral, as metodologias tradicionais de avaliação subestimam o impacto que esta intricada rede de interesses pode ter na execução dos programas e projetos. ${ }^{4}$ No que diz respeito à pesquisa avaliativa, porém, é necessário que haja acordo pelo menos quanto a dois pontos fundamentais: a relevância da avaliação (CoHEN e FrANCO, 1993) e os critérios que definem o sucesso da intervenção (Posavac e CARey, 1992: 32). A existência deste mínimo de consenso entre os atores é condição sine qua non para que os resultados da avaliação gerem reflexões proveitosas sobre as iniciativas governamentais na área social.

A "avaliabilidade" das intervenções também depende de certos atributos do programa ou projeto. Objetivos definidos de maneira vaga e imprecisa podem diminuir o nível de conflito entre os atores relevantes, ${ }^{5}$ mas certamente dificultam (e, no limite, inviabilizam) a realização das pesquisas avaliativas. Portanto, para serem passíveis de avaliação, os programas e projetos devem conter objetivos facilmente identificáveis, além de especificar a clientela visada e o grau de cobertura estabelecido como meta. ${ }^{6}$ Outra questão importante é a disponibilidade e a confiabilidade das informações relevantes.

Em suma, a avaliação desempenha um papel central no esforço de racionalização dos programas e projetos sociais. ${ }^{7} \mathrm{~A}$ ausência de controles e de metodologias de avaliação geralmente leva a um gasto social ineficiente e, conseqüentemente, ao desperdício dos recursos disponíveis. A tendência à expansão dos gastos públicos, especialmente na área social, associada à escassez crônica de recursos fiscais, obriga ao aumento da eficiência ${ }^{8}$ na utilização dos recursos disponíveis e da eficácia $^{9}$ na consecução dos objetivos pretendidos. E são precisamente estes dois vetores - eficiência e eficácia - que orientam a realização das avaliações.

\section{Aspectos-chave do processo avaliativo}

\subsection{A elaboração do projeto de avaliação}

A avaliação propriamente dita é precedida por uma série de tarefas preliminares. A primeira delas é traçar um perfil completo da intervenção, examinando seus objetivos, coletando informações sobre seu mecanismo 
de implementação, conhecendo a equipe responsável e indagando sobre os grupos e indivíduos cujos interesses são afetados pelo seu conteúdo. A segunda tarefa é identificar o cliente e a finalidade da avaliação. É fundamental que se saiba quem demanda informações e para que elas servirão. Porém, autores como Sulbrandt (1993) acreditam que todos os agentes sociais envolvidos na intervenção devem ser vistos como destinatários da pesquisa avaliativa, e não apenas os indivíduos ou instituições que a contrataram. ${ }^{10}$

Nesta fase inicial, procura-se delimitar o objeto de investigação, elegendo os aspectos do programa ou projeto que serão avaliados. Estes, por sua vez, condicionam a escolha do modelo de avaliação. Posavac e Carey (1992) apresentam um panorama das abordagens disponíveis na literatura, que, na prática, podem ser utilizadas conjuntamente. Dentre elas, destacam-se:

a) o modelo de pesquisa em ciência social (social science research model);

b) a avaliação baseada em objetivos (goal-based evaluation);

c) a avaliação de "caixa preta" (black box evaluation), e

d) o modelo naturalista ou qualitativo de avaliação (naturalistic or qualitative evaluation).

A adoção do social research model propicia avaliações mais rigorosas e menos tendenciosas do que o habitual, em virtude do recurso a abordagens experimentais de investigação. É o único modelo que realmente permite que se atribua à intervenção o mérito pelas mudanças observadas na situação-problema. ${ }^{11}$ Não obstante, as conclusões extraídas por seu intermédio devem ser analisadas criticamente, e não tomadas como juízos definitivos sobre o sucesso da intervenção. A avaliação baseada em objetivos, segundo os autores, é mais sensível às especificidades dos projetos e programas, dado que a equipe responsável participa ativamente da definição das questões de avaliação. Este modelo, porém, tem o inconveniente de direcionar excessivamente a pesquisa para objetivos pré-estabelecidos, encobrindo aspectos que podem ser tão ou mais importantes para o processo avaliativo.

A avaliação de "caixa preta", ao contrário, restringe-se ao exame dos resultados, sem nada indagar sobre os objetivos ou o funcionamento do projeto ou programa. Esta abordagem não se presta à melhoria das intervenções, uma vez que desconsidera a explicação que está por trás dos resultados aferidos. Por fim, o modelo naturalista ou qualitativo prioriza a compreensão do significado da intervenção em detrimento da mensuração de seus resultados. O próprio avaliador realiza a investigação, travando contato direto com as instituições e atores relevantes. Porém, esta abordagem imprime à avaliação um caráter mais descritivo do que explicativo. Posavac e Carey recomendam a utilização de modelos ecléticos, visando 
ultrapassar as dificuldades acima mencionadas e suprir as necessidades informacionais de cada pesquisa.

O próximo passo é a definição da estratégia metodológica, que abrange as seguintes dimensões: o desenho da pesquisa, os critérios de avaliação, os procedimentos de amostragem, a coleta de dados, a seleção das técnicas estatísticas e a apresentação dos resultados. Destaca-se a importância da seleção de critérios adequados de avaliação, os quais devem:

a) refletir os objetivos da intervenção;

b) ser mensuráveis; e

c) incorporar a visão dos atores sociais relevantes, principalmente os beneficiários do programa ou projeto.

Estes critérios variam de acordo com o tipo de intervenção e a fase do processo avaliativo em foco, mas há certas perguntas fundamentais que orientam sua elaboração: o programa ou projeto é compatível com os valores dos interessados? Ele atende às necessidades dos clientes/usuários? Ele está sendo implementado como planejado? Seus resultados correspondem aos objetivos visados? ${ }^{12}$ Os pressupostos que informaram a elaboração da intervenção estão explicitados e encontram apoio empírico? Os recursos alocados estão sendo gastos apropriadamente (targetting) e os resultados justificam o gasto realizado? Há critérios sensíveis a efeitos secundários indesejáveis?

Foge aos objetivos deste trabalho aprofundar a discussão sobre as difíceis decisões metodológicas pertinentes à pesquisa avaliativa. Não obstante, na seção sobre avaliação de resultados e de impacto serão feitos alguns comentários neste sentido, particularmente no tocante aos desenhos de investigação (experimentais, quase-experimentais e nãoexperimentais).

\subsection{Tipos de avaliação}

As avaliações podem ser classificadas segundo diferentes critérios, tais como o momento em que se avalia a procedência dos avaliadores, os aspectos da intervenção priorizados e a natureza da questão a ser respondida (Cohen e Franco, 1993; Agullar e Ander-EgG, 1994; Posavac e Carey, 1992). No primeiro caso, distinguem-se as avaliações $e x$-ante, realizadas antes que se inicie o programa ou projeto, das avaliações ex-post, realizadas ao longo da fase de execução ou após a conclusão do mesmo. A avaliação ex-ante visa subsidiar o processo decisório, apontando a conveniência ou não de se realizar o projeto. A avaliação ex-post auxilia os policy sponsors a decidirem pela manutenção e/ou a reformulação do seu desenho original. ${ }^{13}$

Segundo a procedência dos executores, as avaliações classificam-se em externas, internas, mistas e participativas. A opção por cada 
alternativa envolve inescapavelmente ganhos e benefícios. Quando a própria unidade gestora realiza a investigação, minimiza-se o nível de conflito e aumenta-se a quantidade de informação relevante disponível. Em contrapartida, pode-se perder muito em termos de objetividade. Por outro lado, quando se recorre a profissionais não vinculados à instituição executora há um ganho em termos de isenção, mas o acesso aos dados necessários à pesquisa se torna mais difícil.

Uma das classificações mais úteis é a que se baseia nos aspectos do programa ou projeto que são submetidos à avaliação. Aguilar e AnderEgg (1994) sugerem uma tríplice distinção: "avaliação do plano e conceitualização da intervenção, avaliação da instrumentação e seguimento da intervenção (avaliação do processo), e avaliação da eficácia e eficiência da intervenção (avaliação de resultado)". A primeira modalidade julga a pertinência formal e conceitual do programa ou projeto, apontando falhas no diagnóstico ou no próprio desenho da intervenção; a segunda corresponde ao acompanhamento da execução e a terceira à confrontação dos resultados previstos e dos resultados efetivamente obtidos. A avaliação de eficácia, em particular, pode enfatizar os resultados intermediários (avaliação de resultados) ou os resultados finais da intervenção (avaliação de impacto). ${ }^{14}$

A classificação de Posavac e Carey é similar a de Aguilar e Ander-Egg, mas há diferenças importantes de terminologia e até mesmo de conteúdo entre estes autores. Fala-se agora em avaliação de necessidades, avaliação de processo, avaliação de resultados e avaliação de eficiência. Afirma-se que o mapeamento das necessidades (por exemplo, perfil socioeconômico da população-alvo, tipos de carências, formas de prestação de serviço mais atrativas etc.) é essencial para o planejamento da intervenção:

"Evaluators view planning as closely related to evaluation. Planning is, in fact, a form of evaluation - where that occurs before the program is implemented". (POSAVAC e CAREY, 1992: 8)

A avaliação de processo diz respeito à dimensão de gestão. Sua finalidade é julgar se a intervenção está sendo implementada como planejado, se a população-alvo está sendo atingida, se o cronograma está sendo cumprido, se os recursos estão sendo usados com eficiência etc.. Tratase, enfim, do acompanhamento sistemático da evolução das metas do programa ou projeto.

A avaliação de resultados, por sua vez, tem objetivos mais ambiciosos. O primeiro deles é indagar se houve alterações na situação-problema após a intervenção. Em caso afirmativo, deve-se estabelecer uma relação de causalidade entre tais alterações e certos atributos do programa ou projeto. Esta é, sem dúvida, a tarefa mais importante, e também a mais difícil. Se 
for constatada uma correlação positiva entre a intervenção e as mudanças na situação-problema, as hipóteses que informaram a elaboração do programa ou projeto podem ser consideradas válidas. Resta ainda descobrir se elas se aplicam a outras realidades ou se são verdadeiras apenas num determinado contexto.

A análise de resultados, sem dúvida, é a etapa mais complexa do processo avaliativo, especialmente no caso dos programas e projetos sociais, em que se trata de identificar as causas de mudanças que não raro se devem a fatores alheios ao conhecimento do pesquisador. Em termos técnicos, é praticamente impossível controlar todos os preditores que incidem sobre as variáveis-critérios. Além disso, há ainda um outro complicador: mesmo que tenham sido observadas mudanças no comportamento da clientela após a realização do programa ou projeto, e ainda que se conclua que elas estão relacionadas à intervenção, como saber se tais mudanças são permanentes ou apenas temporárias? Por outras palavras, como dizer que uma intervenção foi bem-sucedida sem monitorar o comportamento da população-alvo ao longo do tempo? A próxima seção tenta discutir algumas destas questões sem a pretensão de esgotar um assunto de tamanha complexidade.

Por fim, há ainda a avaliação de eficiência, que permite comparar intervenções alternativas quanto a seus custos. Basicamente, busca-se responder às seguintes indagações:

a) os recursos estão sendo dirigidos aos fins visados?

b) o programa ou projeto funciona a um custo razoável?

c) pode-se valorar monetariamente os resultados atingidos?

d) o programa é tão bem-sucedido quanto outros de custo igual ou menor? Principalmente na área social, os resultados deste tipo de avaliação não devem ser absolutizados, dado que a questão dos custos, ainda que indiscutivelmente relevante, é apenas um dos aspectos a ser levado em conta, quando se decide pela continuidade (ou não) de um programa ou projeto.

Resta ainda salientar, seguindo Posavac e Carey, que a despeito das distinções formais apresentadas, há um forte nexo entre as diferentes modalidades de avaliação, o qual deve-se estar claro para quem realiza estudos desta natureza:

"Without measuring need, programs cannot be planned rationally; without effective implementation, successful outcomes cannot result from the programs; and without valued outcomes, there is no reason to worry about cost-effectiveness. A premature focus on an inappropriate evaluation question is likely to produce an evaluation with little value”. (PosAVAC e CAREY, 1992: 11) 


\section{Avaliação de resultados e avaliação de impacto}

\subsection{Conceitos básicos: eficiência, eficácia, resultados e impacto}

Neste nível de análise, o foco do processo avaliativo é a situaçãoproblema que motiva a elaboração dos planos, programas e projetos. O objetivo do avaliador não é mais apreciar a consistência interna ou a estratégia de implementação de uma dada intervenção, mas indagar sobre as mudanças que ela efetivamente produziu na realidade. Basicamente, a literatura discrimina dois tipos de procedimentos desta natureza: a avaliação de eficiência e a avaliação de eficácia.

$\mathrm{O}$ conceito de eficiência diz respeito à relação entre os resultados e os custos envolvidos na execução de um projeto ou programa. Quando ambos podem ser traduzidos em unidades monetárias, recorre-se à Análise Custo-Benefício (ACB), que, grosso modo, pretende verificar se os benefícios líquidos do projeto excedem seus custos operacionais. Esta técnica não se ajusta à maioria dos projetos sociais, cujos efeitos freqüentemente não podem ser expressos monetariamente. Não obstante, antes de descartar a possibilidade de realizá-la, deve-se atentar para a natureza do problema em foco. Na área social geralmente se utiliza a análise custo-efetividade, que coteja os custos com os produtos e o impacto da interven ção, julgando a eficiência relativa de diferentes estratégias de implementação.

A noção de eficácia se refere ao "grau em que se alcançam os objetivos e metas do projeto na população beneficiária, em um determinado período de tempo, independentemente dos custos implicados (COHEN e FrANCO, 1993: 102). Neste sentido, aferir a eficácia de uma intervenção significa estabelecer um nexo causal entre, de um lado, alguns de seus aspectos e, de outro, eventuais alterações na situação ou nos atributos dos destinatários. Este tipo de avaliação analisa os resultados do programa em termos de efeitos (sobre a clientela atendida) e de impacto (sobre o conjunto da população e o meio). Cabem aqui maiores esclarecimentos sobre cada um destes termos.

Efeito "é todo comportamento ou acontecimento que se pode razoavelmente dizer que sofreu influência de algum aspecto do programa ou projeto" (COHEN e FrAnco, 1992: 91). Ou, de forma mais direta, é todo e qualquer resultado das ações a ele pertinentes. Há, porém, diversos tipos de efeitos, de acordo com a relação que guardam com os objetivos da intervenção: os efeitos procurados e os efeitos não-procurados, que se subdividem em previstos, positivos e relevantes, e os efeitos nãoprevistos. Os primeiros correspondem aos objetivos que a intervenção pretendia atingir, sendo, por definição, previstos e positivos, ao passo que 
os dois últimos equivalem a efeitos indiretos, que podem ser negativos ou positivos, e efeitos inesperados, associados a falhas na elaboração do programa ou projeto e/ou a limitações do conhecimento disponível sobre uma determinada área ou assunto.

Em se tratando de avaliação de resultados, portanto, as questões que se colocam são as seguintes:

a) o programa ou projeto surtiu algum efeito sobre a população-alvo?

b) em caso afirmativo, como classificar tais efeitos? (diretos, indiretos etc.). O passo seguinte do processo avaliativo é estimar o impacto do programa ou projeto, entendido como a resultante dos efeitos por ele produzidos. $^{15}$

Para esclarecer este ponto, pode ser útil recorrer à imagem de uma "reação em cadeia": a intervenção produz certos efeitos no grupo visado, os quais, por sua vez, repercutem sobre o restante da população e/ou sobre o ambiente social. A diferença entre a avaliação de resultados e avaliação de impacto, portanto, depende eminentemente do escopo da análise: se o objetivo é inquirir sobre os efeitos de uma intervenção sobre a clientela atendida, então trata-se de uma avaliação de resultados; se a intenção é captar os reflexos desta mesma intervenção em contexto mais amplo, então trata-se de uma avaliação de impacto. Ou, dito de outra forma, a avaliação de resultados visa aferir os resultados intermediários da intervenção, e a avaliação de impacto, seus resultados finais.

As análises de impacto apontam a efetividade ${ }^{16}$ de programas e projetos, estabelecendo o grau de correspondência entre seus objetivos e resultados. Elas podem ser prospectivas ou retrospectivas. Há, porém, alguns pré-requisitos para a realização de avaliações desta natureza, quais sejam:

a) os objetivos da intervenção devem estar definidos de maneira a permitir a identificação de metas mensuráveis;

b) sua implementação deve ter ocorrido de maneira minimamente satisfatória, pois, caso contrário, não faria sentido tentar aferir impacto. Isto significa que problemas no desenho e/ou na execução dos programas prejudicam a qualidade dos processos avaliativos e, no limite, podem chegar mesmo a inviabilizá-los.

\subsection{Desenhos de investigação e causalidade}

As análises de impacto visam estabelecer relações de causalidade, que, no campo das ciências sociais, se definem em termos de probabilidades. Segundo Rossi e Freeman (1989: 5), "el problema critico del análisis de impacto es determinar si un programa produce efectos diferentes a lo que habría ocorrido sin la intervención o con una intervención alternativa". Para Cheibub Figueiredo e Figueiredo (1986), certos tipos 
de políticas públicas, como, por exemplo, os programas e projetos sociais, só podem ser considerados bem-sucedidos...

“... quando se pode imputar aos mesmos a condição de causa necessária, quando não suficiente, de uma mudança observada. Ou seja, a constatação de que ocorreram mudanças não é suficiente para concluir-se pelo sucesso de um programa: é necessário demonstrar que elas não ocorreriam (total ou parcialmente) sem o programa." (Cheibub Figueiredo e Figueiredo, 1986: 115).

Neste sentido, a escolha do desenho de investigação é decisiva. As abordagens não-experimentais, menos complexas e custosas, são inadequadas para a determinação de nexos causais, devido às suas deficiências em termos de validade interna:

"Internal validity refers to being able to conclude that an independent variable (such as the program) caused a change in a dependent variable (such as a measure sensitive to the behavior) the program was supposed to improve." (PosAvAC e CAREY, 1992: 141).

Os conceitos de resultado bruto e resultado líquido permitem esclarecer melhor este ponto:

"Los resultados brutos los conformam todos los cambios que se observan en una medición de resultados quando se avalia un programa. Es más dificil medir los resultados netos. Estos resultados son aquellos que se pueden atribuir razonablemente a la intervención, libres de los efectos de cualquier otra causa que pueda estar ejerciendo influencia. Los resultados brutos, por supuesto, incluem los resultados netos". (Rossi e FREEMAN, 1989: 6)

Segundo os autores, "os resultados brutos compreendem os efeitos da intervenção (resultado líquido), os efeitos de outros processos (fatores estranhos) e os efeitos do desenho da avaliação" (Rossi e FreEman, 1989: 6). Ou seja, o resultado bruto reflete não só as conseqüências da intervenção, mas também os efeitos de processos externos e simultâneos a ela. Portanto, para se chegar a uma estimativa de impacto confiável, devese eliminar explicações das mudanças observadas que não se relacionam com a intervenção em foco.

É precisamente isso que as abordagens não-experimentais são incapazes de fazer: discriminar os preditores e apontar o peso relativo de cada um deles na conformação dos resultados observados. Os fatores intervenientes (ou, nos termos de Posavac e Carey, as "ameaças à validade interna") se incluem em três categorias: processos alheios à intervenção, processos relativos aos participantes e processos pertinentes ao desenho da avaliação. 
A primeira categoria abrange:

a) as mudanças endógenas, que resultam de cursos "naturais" de evolução, podendo levar os avaliadores a atribuir à intervenção eventos que teriam ocorrido de qualquer maneira;

b) as tendências seculares, sociais ou organizacionais, que podem aumentar ou obscurecer o impacto de uma intervenção;

c) os eventos de interferência, que se assemelham às tendências seculares mas se referem a um horizonte de curto prazo, e;

d) as tendências de maturação, que têm a ver com programas e projetos dirigidos a uma população-objeto com idade determinada, cujo amadurecimento pode produzir mudanças que simulem ou encubram os efeitos da intervenção. Há também os processos afetos aos participantes do programa ou projeto:

— Seleção não controlada. Se o grupo submetido à intervenção é formado por voluntários, o pesquisador enfrenta um sério problema. Os indivíduos, que se candidataram, podem ser substancialmente diferentes dos membros típicos da população-alvo, pelo menos em termos de motivação. Estes diferentes "pontos de partida" dificultam a comparação dos resultados deste grupo com os resultados de grupos formados aleatoriamente;

— Mortalidade ou "des-seleção". É o inverso da seleção não controlada. Com o tempo, alguns participantes vão se desmotivando, e outros chegam mesmo a abandonar o programa ou projeto. Pode-se supor que os indivíduos que permanecem até o final estavam mais preparados para a intervenção do que aqueles que se evadem;

— Regressão à média. Este processo diz respeito às oscilações no desempenho dos participantes dos programas e projetos. A explicação para tais oscilações nada teria a ver com a intervenção, mas com uma tendência "natural" de retorno à média. Assim, após um desempenho extremo (alto ou baixo), seria razoável esperar uma performance mais moderada (ou mais próxima da média).

Segundo Posavac e Carey, as dificuldades criadas pela seleção e "des-seleção" não controladas podem ser contornadas por meio da realização de um pré-teste:

"By pretesting, evaluators know how has dropped out and how they compared to those who remained. The pretest-posttest design enables evaluators to know when preprogram achievement and participant dropout are not plausible explanations for the level of outcome observed at the end of the program. (POSAVAC e CAREY, 1992: 149)

O grau em que os processos acima mencionados afetam as análises de impacto varia de acordo com os fenômenos sociais e as intervenções 
em foco. Os efeitos de desenho, ao contrário, sempre ameaçam a sua validade, pois decorrem do próprio processo de investigação. Dentre eles, pode-se destacar:

a) os efeitos causais, que se referem à dificuldade de estimar a magnitude dos resultados considerados significativos;

b) as deficiências de confiabilidade e validade das medições, em função dos instrumentos analíticos utilizados;

c) a dificuldade de escolher modelos de investigação capazes de representar adequamente as metas e objetivos do programa; e

d) as insuficiências de informação. ${ }^{17}$

Posavac e Carey identificam ainda dois outros problemas:

a) o efeito teste, que se refere a mudanças comportamentais produzidas pelas próprias técnicas de observação (constatou-se que a familiaridade dos participantes com os métodos de pesquisa afeta o resultado da avaliação); e

b) o efeito instrumentação, pertinente ao uso de procedimentos de mensuração que envolvem algum grau de subjetividade (os próprios avaliadores podem influenciar os resultados da avaliação, por exemplo, ao adquirirem maior capacidade de análise no decorrer da pesquisa).

Não obstante, estas dificuldades podem ser parcialmente contornadas. ${ }^{18}$ Certas estratégias de investigação permitem que se controle a influência dos fatores intervenientes sobre os resultados observados. $\mathrm{O}$ pesquisador deve selecionar aquela que melhor atenda às suas necessidades, de acordo com a disponibilidade de recursos materiais e humanos e as especificidades da intervenção a ser examinada. O próximo tópico trata do uso de abordagens experimentais e quase-experimentais para a realização de avaliações de resultados e impacto.

\subsection{Abordagens experimentais e quase-experimentais}

Para estabelecer uma relação de causalidade, é necessário demonstrar que a causa precede o efeito no tempo, que a causa e o efeito variam simultaneamente e no mesmo sentido, e que não existe nenhuma explicação alternativa para o efeito além da causa explicitada. Apenas desenhos de investigação rigorosos permitem que se responda a estas três perguntas. Os especialistas recorrem a certas estratégias para aumentar o rigor das avaliações, tais como: observar os participantes diversas vezes antes e depois da intervenção; observar indivíduos que não foram expostos ao programa ou projeto.

As abordagens que recorrem a estes expedientes são denominadas experimentais ou quase-experimentais. Ambas baseiam-se na constituição de dois ou mais grupos: o grupo experimental, que recebe os estímulos do programa ou projeto em foco, e o grupo de controle, que não é exposto a 
nenhum estímulo ou recebe tratamento alternativo. A lógica que informa o modelo é, na verdade, bastante simples. Deve-se comparar a situação dos grupos antes da intervenção com a situação em que se encontram depois dela, para verificar se houve quaisquer mudanças. ${ }^{19}$ Há, porém, uma diferença fundamental entre estes desenhos de investigação:

"A true experimental evaluation refers to an evaluation based on observations of people randomly assigned to the program group or to some control group". (POSAVAC e CAREY, 1992: 179)

Segundo Rossi e Freeman, o desenho de investigação que melhor se presta à determinação da causalidade é o modelo experimental. A seleção aleatória viabiliza a formação de amostras representativas e homogêneas, ampliando a comparabilidade dos resultados pertinentes aos grupos experimental e de controle. Esta opinião é compartilhada por diversos autores:

"Para o controle do experimento e para evitar vieses na seleção dos membros de cada grupo é fundamental a aleatorização. A determinação ao acaso, baseada na casualidade, faz com que cada efeito particular... tenha uma probabilidade igual e independente de ocorrer', com o que 'os resultados serão simétricos no sentido de que para cada efeito negativo possível haverá um efeito positivo correspondente' (FISCHER cit. em GreEnwood, 1951, 136). Assim, os fatores incontroláveis, dos quais não se sabe que efeitos exercem sobre o resultado procurado, se distribuirão ao acaso." (COHEN e FRANCO, 1993: 12)

O modelo experimental é de difícil operacionalização, mas autores como Posavac e Carey sustentam que os custos de optar por experimentos menos rigorosos são proibitivos, principalmente nas seguintes situações:

a) quando se decide implementar um novo programa ou projeto;

b) quando a intervenção é ambiciosa em termos de recursos ou de pessoas afetadas;

c) quando há controvérsia sobre a efetividade de uma intervenção; e

d) quando é necessário reformular um programa ou projeto, mas não se sabe como. Os modelos quase-experimentais são a segunda melhor alternativa à disposição do pesquisador:

"Quasi-experimental methods are useful when evaluators do not have the administrative power or when it's unethical to assign people to particular experiences. In such settings evaluators utilize preexisting intact groups; however, such intact groups were formed for reasons other than the need for an 
unambiguosly interpreted evaluation. Because such groups

exist of their own accord, it is very likely that the groups differ on many variables. We also mentioned several appoaches to making groups more comparable - matching, finding similar intact groups, or using a statistical adjustement". (PosAVAC e CAREY, 1992: 179)

Se cuidadosamente planejados e executados, os quase-experimentos permitem o controle de diversos vieses e geram resultados razoavelmente confiáveis. A combinação de certas modalidades, como a análise de séries temporais e os grupos de comparação não-equivalentes, possibilita a discriminação entre mudanças na situação-problema suscitadas pela intervenção e meras flutuações aleatórias. A coleta de informações em múltiplos intervalos de tempo visa identificar tendências prévias à intervenção e detectar a ocorrência e a perenidade das mudanças observadas:

"Time-series approach to program evaluation minimally includes the following characteristics: (1) a single unit is defined, and (2) quantitative observations are made (3) over a number of time intervals (4) that precede and follow some controlled or natural intervention (KNAPP, 1977). In the language of experimental design, the unit observed (person, group, or nation) serves as its own control'. (PosAvAC e CAREY, 1992: 162)

$\mathrm{Na}$ ausência da aleatorização, o grande problema é obter grupos experimentais e de controles similares suficientes para permitir comparações minimamente válidas. Uma alternativa é utilizar o grupo experimental como parâmetro para escolher os integrantes do grupo de controle (matching). Esta abordagem só é viável se não houver auto-seleção dos participantes e se o nível de necessidade da clientela não for o principal critério de elegibilidade para o programa ou projeto. Mesmo nestes casos, este desenho de investigação é bastante sensível a certas "ameaças à validade interna" das avaliações. Por exemplo, se os componentes dos grupos diferirem sistematicamente quanto a certas dimensões, o efeito de regressão à média poderá ser bastante significativo.

\section{Considerações finais: críticas aos modelos tradicionais de avaliação}

As metodologias de avaliação de programas sociais têm sido objeto de severas críticas. Basicamente, afirma-se que, na prática, as avaliações não subsidiam o processo decisório porque seus resultados são inconclusivos, inoportunos e irrelevantes. Inconclusivos em função das próprias limitações deste tipo de estudo, inoportunos devido à morosidade 
do processo avaliativo e irrelevantes, porque não respondem às demandas informacionais de todos os agentes sociais afetos à intervenção. A explicação para tais deficiências residiria nos próprios pressupostos que informam este tipo de estudo:

"Lo que subyace a estos intentos de evaluación es una concepción normativa-formal de las políticas e programas públicos, de las organizaciones gubernamentales y de los procesos de implementación. Se presume que a través de conductas prescritas de antemano en un plan de ejecución se llevarán a cabo un conjunto de acciones precisas que permitirán alcanzar los fines propuestos. Este tipo de ejecución ha recibido la denominación de implementación programada."(SULBRANDT, 1993: 323-24)

Para o autor, esta concepção de implementação seria pouco realista, e, pior ainda, teria um viés nitidamente tecnocrático. Estar-se-ia ignorando por completo as restrições impostas pelos contextos social, político e organizacional onde a implementação ocorre. Certamente, tais restrições potencializam a complexidade e a incerteza inerentes a esse processo, desautorizando as abordagens que partem do pressuposto de que os policy makers controlam o processo organizacional, político e técnico, associado à implementação de políticas:

“A implementação é definida no processo em que a política governamental envolve-se com sujeitos não-governamentais, sendo alguns deles objetos da política com poder de ação, recursos e idéias. Implementação é, portanto, uma relação entre atores (governamentais e não-governamentais), na qual estes ganham status de sujeitos intencionais". (VIANA, 1996: 20)

Portanto, o sucesso da implementação não seria decidido na cúpula do governo ou da organização, mas em embates contínuos no interior da burocracia pública e na intersecção entre ações administrativas e escolhas privadas. A resultante deste processo dependeria dos recursos de poder e das estratégias dos atores relevantes, bem como das especificidades das organizações responsáveis pela intervenção. O equívoco da concepção da "implementação programada" e dos enfoques tradicionais de avaliação seria superestimar a capacidade governamental de conformar a conduta dos burocratas do street-level, dos grupos-objetivos e de outros atores sociais vinculados à intervenção.

Estas críticas estimularam a reflexão sobre novas formas de conceber e executar a avaliação de programas sociais. No entanto, os representantes do paradigma minoritário, que reúne enfoques baseados 
na fenomenologia, na etnometodologia e no interacionismo simbólico, são considerados, no mínimo, controversos. Geralmente, além de carecerem de rigor metodológico, tais enfoques tendem ao extremo oposto das concepções tradicionais, priorizando a descrição em detrimento da explicação e supervalorizando a dimensão política do processo de implementação. Há autores, porém, que pretendem ter encontrado a síntese entre estas concepções polares de avaliação:

"La evaluación global pretende complementar los enfoques tradicionales con otros renovados, de forma tal, que en conjunto muestren sus logros y junto a ellos distinctos factores significativos del programa, su implementación en um determinado medio institucional e social, la acción de los distinctos grupos significativos vinculados al programa de forma de completar lo que falta a los diseños clássicos pero manteniendo su nível de análisis y su alto grado de rigor". (SULBRANDT, 1993: 324)

Basicamente, esta perspectiva abrange os seguintes aspectos: a utilização de múltiplos critérios de avaliação, de modo a incorporar a visão dos diversos atores vinculados à intervenção; o exame do arranjo institucional e do ambiente organizacional relativo ao programa ou projeto; a análise dos recursos de poder e das estratégias dos atores sociais relevantes; o exame do modelo causal subjacente às intervenções sociais; o recurso a um desenho de investigação complexo e metodologicamente eclético, que combine diferentes critérios (eficiência, eficácia, eqüidade etc.) e enfoques metodológicos (objetivos e subjetivos).

Não se pode negar à Sulbrandt o mérito de colocar em discussão uma série de pressupostos claramente equivocados acerca da formulação e implementação de políticas públicas. Entretanto, pelo menos à primeira vista, sua concepção de avaliação está sujeita às mesmas críticas que o autor dirigiu ao enfoque tradicional. Aliás, suspeita-se até que sua proposta gere resultados ainda menos conclusivos, oportunos e relevantes do que as abordagens-padrão, tendo em vista a sua complexidade e dificuldade de operacionalização. A bem da verdade, a impressão que fica é que se trata não de uma, mas de várias pesquisas avaliativas superpostas, e no limite, incompatíveis. Evidentemente, ainda há muito o que discutir sobre as metodologias de avaliação de programas e projetos sociais. 
1 Atividades são ações que permitem gerar um determinado produto, sendo, em geral, repetitivas, apesar de não serem necessariamente contínuas.

2 Segundo Cohen e Franco (1993: 85-6), projeto é o "empreendimento planejado que consiste num conjunto de atividades inter-relacionadas e coordenadas para alcançar objetivos específicos, dentro dos limites de um orçamento e de um período de tempo dados (ONU, 1984). É, portanto, a unidade mais operativa dentro do processo de planejamento e constitui o elo final de tal processo. Está orientado à produção de determinados bens ou a prestar serviços específicos".

3 Objetivo é a situação que se deseja obter ao final do período de duração do projeto, mediante a aplicação dos recursos e da realização das ações previstas. Diferencia-se da meta, que pode ser definida como "um objetivo temporal, espacial e quantitativamente dimensionado". Os objetivos, explícitos ou latentes, podem ser classificados como: de resultado e de sistema, originais e derivados, gerais e específicos, únicos e múltiplos, complementares, competitivos e indiferentes, imediatos e mediatos (COHEn e Franco, 1993: 88-90).

4 As principais críticas às metodologias tradicionais de avaliação serão sumariadas e discutidas na última seção do trabalho.

5 Posavac e Carey (1992) afirmam que este é um expediente relativamente comum, que visa diminuir o grau de antagonismo nas fases de construção da agenda e formulação de políticas públicas, transferindo o conflito para o momento em que já se tenha criado, pela implementação do programa ou projeto, um "fato consumado".

6 Segundo Cohen e Franco (1993: 90-5), cada programa ou projeto tem uma clientela (população-objetivo, grupo focal etc.), isto é, um grupo de pessoas a quem ele se destina. "As medições de avaliação são realizadas sobre indivíduos ou grupos de indivíduos que possuem em comum algum atributo, carência ou potencialidade que o projeto pretende suprir ou desenvolver". A cobertura, por sua vez, é dada pela proporção entre o contingente que efetivamente recebe os serviços e a parcela da população cujas necessidades o projeto pretende atender.

7 Como bem mostram Cohen e Franco (1993), a avaliação não é apenas um instrumento para determinar em que medida os projetos sociais alcançam seus objetivos. Sua pretensão é, em última instância, racionalizar a alocação de recursos, através do aprimoramento contínuo das ações que visam modificar segmentos da realidade.

8 O conceito de eficiência está associado à noção de "ótimo" (quantidades físicas mínimas de recursos requeridos para gerar uma certa quantidade de produto, assumindo a tecnologia como constante).

9 Eficácia é o grau em que se alcançam os objetivos e metas do projeto na população beneficiária, em determinado período de tempo, independentemente dos custos implicados. Os conceitos de eficiência e eficácia diferenciam-se do conceito de efetividade, que corresponde à relação entre os resultados e os objetivos do projeto. A discussão sobre tais conceitos será retomada na última seção deste capítulo.

${ }^{10}$ Segundo Sulbrandt (1993: 323), é devido a este viés que os resultados das avaliações geralmente se tornam irrelevantes. Este ponto é retomado nas considerações finais deste trabalho.

11 As abordagens experimentais e quase-experimentais, bem como o estabelecimento de relações de causalidade, serão analisadas em detalhe na seção sobre avaliação de resultados e de impacto. 
${ }^{12}$ Posavac e Carey advertem que, para responder a esta indagação, é necessário estabelecer objetivamente qual é a expectativa de mudança na realidade ou de melhoria na situação da clientela.

13 As avaliações ex-ante podem ser consideradas avaliações formativas, porque seu propósito é auxiliar a concepção e a estruturação do programa ou projeto; as avaliações ex-post, por sua vez, correspondem a avaliações somativas, pois subsidiam a tomada de decisões sobre uma intervenção que já está em andamento.

14 Segundo Cohen e Franco (1993), o impacto é definido como "os resultados dos efeitos de um projeto" (ONU, 1984). Os efeitos, por sua vez, derivam da utilização dos produtos do projeto, sendo os produtos os resultados concretos das atividades desenvolvidas a partir dos insumos disponíveis. Trocando em miúdos: os efeitos corresponderiam aos resultados e objetivos intermediários da intervenção e o impacto a seus resultados e objetivos finais.

15 Godfrey (1996) ao analisar o impacto de programas de treinamento enfatiza a interação entre diversos tipos de efeitos indiretos, tais como o efeito remoção, o efeito substituição, o efeito demonstração, os efeitos sociais e efeito de diminuição de gargalos.

16 Segundo Cohen e Franco (1993), o conceito de efetividade tem a ver com os resultados concretos - ou as ações a ele conducentes — associados aos fins, objetivos e metas desejadas.

${ }^{17}$ Rossi e Freeman (1989: 20) citam ainda o Efeito Hawthorne, segundo o qual "todo aspecto del sistema de entrega de la intervención, incluyendo la planta física, las normas e regulaciones y la classificación de los grupos objetivo, puede afectar tanto los resultados de la intervención, que el monitoreo de la entrega de intervenciones quasi sempre es un auxiliar necesario para los análisis de impacto".

18 Segundo Posavac e Carey (1992), o problema é que, geralmente, as "ameaças à validade interna" das avaliações aparecem combinadas, dificultando ainda mais o trabalho do pesquisador. Há, também, a possibilidade dos resultados estarem sendo afetados por fatores não identificados, que podem simular ou esconder os verdadeiros efeitos da intervenção.

19 Cohen e Franco (1993) ressaltam que o "antes" não precisa ser um momento anterior ao início do projeto, nem o "depois" um momento posterior à sua finalização. Tratase, em vez disso, de momentos definidos de acordo com a natureza dos objetivos que o projeto pretende alcançar e o grau de sensibilidade dos indicadores utilizados na pesquisa avaliativa. 


\section{Referências bibliográficas}

Aguillar, M.J. e Ander-EgG, E. (1994), Avaliação de serviços e programas sociais. Petrópolis, RJ: Vozes.

Cheibub Figueiredo, A. e Figueiredo, M. (1986), "Avaliação política e avaliação de políticas: um quadro de referência teórica". Análise e Conjuntura, Belo Horizonte: Fundação João Pinheiro, v. 1, n.3, set/dez., p. 107-127.

Cohen, E. e Franco, R. (1993), Avaliação de projetos sociais. Petrópolis, RJ: Vozes.

EBAP/FGV. (1992), "Projeto: avaliação de programas públicos" (Síntese do documento produzido pelo General Accounting Office - GAO/PMED, 10.1.2, march 1992. "The Evaluation Synthesis", RJ: Brasil).

Godfrey, M. (1987), "Monitoring the utilization of educated manpower", in Monitoring Labour Markets, International Labour Organization.

ONU, Grupo do CAC. (1984), Seguimiento y evaluación. Pautas básicas para el desarrolo rural. Roma: FAO.

Posavac, E.J. e Carey, R.G. (1992), Program evaluation: methods and case studies. Englewood Cliffs, New Jersey: Prentice Hall, $4^{\mathrm{a}}$ ed.

Rossi, P. e Freeman, H. (1989), Evaluación: un enfoque sistematico. Sage Publications Inc., caps. IV e V.

SULBRANDT, J. (1993), La evaluacíon de los programas sociales: una perspectiva crítica de los modelos usuales. CLAD.

VIANA, A.L. (1996), “Abordagens metodológicas em políticas públicas”. RAP, v.3, n.2, mar/abr., p. 5-43. 


\section{Metodologias de avaliação de programas e projetos sociais: análise de resulta- dos e de impacto}

Tereza Cristina Cotta

O trabalho versa sobre as metodologias de avaliação de programas e projetos sociais, enfatizando modalidades avalistas específicas, as análises de resultados e impacto. Após o exame de conceitos básicos e tipologias de avaliação consagradas pela literatura, faz-se alguns comentários sobre os modelos tradicionais de avaliação.

\section{Metodologías de evaluación de programas y proyectos sociales: análisis de re- sultados y de impacto}

\section{Tereza Cristina Cotta}

El trabajo versa sobre las metodologías de evaluación de programas y proyectos sociales, enfatizando modalidades valuadoras específicas, los análisis de resultados y el impacto. Después del examen de conceptos básicos y tipologías de evaluación consagradas por la literatura, se hacen algunos comentarios sobre los modelos tradicionales de evaluación.

\section{Methodologies for evaluation of social programs and projects: results and impact analysis}

\section{Tereza Cristina Cotta}

The theme of this work is the methodologies of evaluation of social programs and projects, stressing specific kinds of evaluation, the results and impact analysis. After the exam of basic concepts and widely accepted evaluation typologies, some comments are maid about traditional evaluation models.
Revista do

Serviço

Público

Ano 49

Número 2

Abr-Jun 1998

Mestre em

Ciência Política pelo DCP/ FAFICH/UFMG

e Especialista em Políticas Públicas e

Gestão

Governamental 